\title{
Combination between Mifepristone and Methotrexate to Treat Ectopic Pregnancy: A Systematic Review Protocol
}

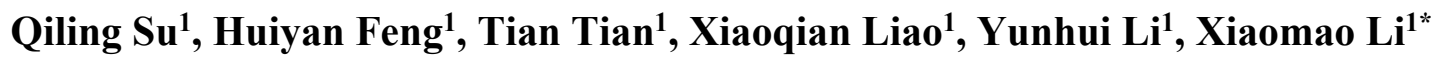 \\ ${ }^{1}$ Department of Gynecology, The Third Affiliated Hospital of Sun Yat-Sen University, Guangzhou, \\ China
}

* Correspondence:

Xiaomao Li

lixmao@mail.sysu.edu.cn

Keywords: ectopic pregnancy ${ }_{1}$, mifepristone $_{2}$, methotrexate ${ }_{3}$, randomized controlled trials $_{4}$, PRISMA5, meta-analysis6

\begin{abstract}
Background: In recent years, the morbidity of ectopic pregnancy and the proportion of young and childless patients have increased year by year, which makes it important to early diagnose EP, effectively save patients' lives and furthest preserve their fertility. Methotrexate and mifepristone are most widely used in conservative treatments, however, there is no accurate conclusion about which therapy is better. Therefore, the aims in this meta-analysis are, on the one hand, to systematically analyze the efficacy of mifepristone combined with methotrexate in the treatment of ectopic pregnancy through existing studies, and to draw scientific conclusions. On the other hand, to fill the gap of relevant analysis in China and abroad, to evaluate the advantages and disadvantages of inclusion trials and propose improvement measures and scientific designing schemes.
\end{abstract}

Methods: Six electronic databases will be searched, including PubMed, Embase, Cochrane Library, the China National Knowledge Infrastructure(CNKI), Chinese Science and Technology Periodical Database (VIP), and Wanfang Database (WF). Literature from October 2015 to October 2020 on randomized controlled trials will be searched, without any language or publication restriction. Search terms include mifepristone, methotrexate, ectopic pregnancy, and random (free word/synonym expansion). Included in a randomized controlled trial, the treatment group was treated with mifepristone combined with methotrexate, and the control group was treated with mifepristone alone. Revman 5.4 (provided by Cochrane) will be used to evaluate the quality of the literature, and the corresponding effect model will be selected to analyze the results. The cure rate will be the main outcome index, and the remaining outcome measures after literature inclusion will be the secondary outcome indexes.

Result: Only when we finish this meta-analysis can we get the result.

Discussion: The results of this study will provide reliable evidence for the efficacy of mifepristone combined with methotrexate therapy in the treatment of ectopic pregnancy.

NOTE: This preprint reports new research that has not been certified by peer review ardd should not be used to guide clinical practice. 
medRxiv preprint doi: https://doi.org/10.1101/2021.09.26.21264155; this version posted September 29, 2021. The copyright holder for this

preprint (which was not certified by peer review) is the author/funder, who has granted medRxiv a license to display the preprint in

All rights reserved. No reuse allowed without permission.

\section{PROSPERO registration number: CRD42021246757}

\section{Article Summary}

Strengths and limitations of this study: This study will systematically analyse the efficacy of combination between mifepristone and methotrexate to treat ectopic pregnancy and comes to a scientific conclusion. This study will fill the gap of relevant analysis in China and abroad. This study will evaluate the advantages and disadvantages of inclusion trials. This study will find out the reasons why most of the research results are not reliable enough, and propose measures for and scientific designing schemes. The quality of the trials may be generally low.

\section{Introduction}

Ectopic pregnancy is when blastocyst is implanted outside the uterus, most of which is fallopian tube pregnancy. Ectopic pregnancy is a common clinical acute abdominal disease in obstetrics and gynecology, as well as one of the primary causes of maternal death. In recent years, the incidence of ectopic pregnancy has increased year by year and has shown a trend of patients of younger age. Domestic literature in China reports that the minimum age of onset of ectopic pregnancy is 16 years old[1], besides, the incidence rate in pregnant women is $2 \%$ while the mortality rate accounts for about $10 \%$ of the total maternal deaths [2]. In Liu Ying's study, the incidence rate increased from $2.48 \%$ in 2005 to $4.36 \%$ in 2012 , and the proportion of conservative treatment increased from $7.14 \%$ to $20.73 \%$ [3]. Tang Lirong analyzed the factors associated with the incidence of ectopic pregnancy in patients from October 1997 to September 1998 (the latter group) and from October 2007 to September 2008 (the former group). The proportion under 20 years old in the later group increased from $1.1 \% 10$ years ago to $4.5 \%$. Unmarried women increased from $21.5 \%$ to $41.4 \%$; The number of childless women rose from $45.7 \%$ to $66.8 \%$ [4]. Therefore, patients with ectopic pregnancy tend to be younger, unmarried, and childless.

Since embryo implantation in the uterus is a complex developmental process, the molecular interaction mechanism is still unclear, especially for tubal ectopic pregnancy. What is certain is that once pregnant, the trophoblast cells begin to secrete a large amount of hCG, and at the same time, the trophoblast cells also secrete substances that can distinguish between normal pregnancy and abnormal pregnancy.[5] Research has shown that the $\beta$-HCG level of EP patients is lower than that of normal pregnant women because blastocyst cannot receive enough blood supply, the development of the placenta is limited and the trophoblast layer is mostly dysplastic [6]. Therefore, $\beta$-HCG level can be used as an index of diagnosis and differential diagnosis of ectopic pregnancy. On the other hand, EP can be difficult to detect in the early stage, but as the disease progresses, the gestational sac (mass) will grow, and the patient may experience sudden and intense abdominal pain, or irregular vaginal bleeding, and other symptoms. The clinical symptoms above can be detected by ultrasound examination, which can also be considered as an appropriate tool for the diagnosis of EP.

In conclusion, because of the increasing incidence of ectopic pregnancy, early diagnosing and treating EP patients in order to effectively save their lives and furthest preserve fallopian tube function and fertility is particularly important. Meanwhile, because of the various diagnostic methods, the spread of hygienic knowledge, and the wide application of transvaginal ultrasound examination 
medRxiv preprint doi: https://doi.org/10.1101/2021.09.26.21264155; this version posted September 29, 2021. The copyright holder for this

preprint (which was not certified by peer review) is the author/funder, who has granted medRxiv a license to display the preprint in

All rights reserved. No reuse allowed without permission.

and $\beta$-HCG test, it is possible to early diagnose EP and create opportunities for conservative treatment.

Drug therapy is one of the conservative treatments of EP, which first appeared in the 1980s and is still widely used nowadays. It is confirmed that drug therapy can prevent patients from surgical trauma and complications, such as pelvic adhesion, and furthest preserve fallopian tube function and increase fertility rate [7]. Nowadays, the common drugs include methotrexate, mifepristone, hypertonic glucose, prostaglandin, potassium chloride, fluorouracil, traditional Chinese medicine, etc., among which methotrexate and mifepristone are most widely used, and they are often used in combination for clinical application.

Mifepristone is a steroidal anti-progesterone drug, the main principle of its treatment of ectopic pregnancy is: blocking the secretion of progesterone to shrink corpus luteum, causing cells degeneration, decidua, and chorion decrease. Mifepristone can also promote the release of endogenous prostaglandins, causing uterine contractions, cervical softening and dilation, and assisting ectopic embryo tissue discharge [8].

The specific mechanism to function includes two stages: molecular mechanism and biological effect. Among them, the process of molecular mechanism is: (1) It competitively binds to the progesterone receptor activation domain, thereby antagonizing progesterone activity. The progesterone receptor(PR) has three independent isomers(PR-A, PR-B, PR-C), and PR-A has two transcription activation domains that mainly mediate endometrial hyperplasia [9] and progesterone binds to the 42-amino acid sequence at PR-C to exert biological effects. But mifepristone can bind to the hormone-binding domain at the PR-N tail due to the characteristics of its phenyl group at the $11 \beta$ site, thus, progesterone is 5 times stronger than PR affinity, which antagonizes the progesterone activity. (2) It has initiating/inhibiting effects: Mifepristone can effectively activate inhibiting factors, such as nuclear receptor corepressor (NCOR), retinoic acid silencing mediator, etc. It can also activate promoters of target genes of the response element, and its initiation/inhibition effects depend on the relative concentration of the promoters/repressors produced [10]. (3) Mifepristone has a high affinity with glucocorticoid receptor (GR) and relatively weak interactions with other steroid hormone receptors [11].

The biological effects of mifepristone can be divided into early and long-term effects. The early effects are as follows: (1)it acts directly on villus issue, prevents the mitosis of villus cells from $\mathrm{G}_{0}, \mathrm{G}_{1}$ phase to $\mathrm{S}$ phase, induces and promotes apoptosis, and leads to the necrosis of decidual cells [12]; (2)it lowers the expression of osteopontin in villus cells, increases the expression of the inhibitory factor of leukemia and interleukin- 6 messenger mRNA, and promotes the apoptosis of villus cells [13]; (3)it acts on the blood vessels of the endometrium, causing blood vessel damage, and further damaging the internal environment needed for implantation and growth; (4)it reinforces the gap junctions between muscular cells, promotes the influx of calcium ions and improves the excitability of muscle cells; (5)it increases the sensitivity of muscle cells to exogenous prostaglandins and strengthens uterine contraction; (6)it inhibits prostaglandin dehydrogenase thereby increasing intracellular prostaglandin release and inducing prostaglandin accumulation (7)it promotes nitric oxide(NO) to release, expresses inducible NO synthase and promotes cervical dilation. 
medRxiv preprint doi: https://doi.org/10.1101/2021.09.26.21264155; this version posted September 29, 2021. The copyright holder for this preprint (which was not certified by peer review) is the author/funder, who has granted medRxiv a license to display the preprint in All rights reserved. No reuse allowed without permission.

The long-term effects are as follows: (1)It inhibits endometrial hyperplasia, mitotic activity, and secretory activity, and reduces endometrial thickness; (2)it increases the number of estrogen receptors $(\mathrm{PR})$ and androgen receptors, and enhances the inhibition of androgen on endometrium [9-10]; (3)it lowers the expression of stromal vascular endothelial growth factor (VEGF) protein, causes damage to endometrial vessels and induces endometrial atrophy; (4)it inhibits ovulation and delays menstruation; it can also affect the function of hypothalamic-pituitary-ovarianaxis when used in large doses; (5)the inhibition of endometrium leads to reduced menstruation and even amenorrhea. After amenorrhea, the estradiol level is still in the range of the early follicular stage in the menstrual cycle[14].

Mifepristone can be used clinically to treat ectopic pregnancy. In the clinical treatment of ectopic pregnancy, it can be directly taken orally. It is convenient to use and carry the medicine, which can effectively prevent the medicine from being contaminated; For patients with early ectopic pregnancy, it can effectively maintain the integrity of the fallopian tube, avoid affecting the patient's fertility, thereby increasing the patient's natural re-pregnancy rate. However, Fiscella J[15] has shown that long-term use of mifepristone can lead to asynchronous endometrium, large fluid-filled glands with dilated, stratified nuclei, cells atypia, cells metaplasia, and cells mitosis, abnormal blood vessels, including vascular dilatation, thin-walled vessels, reticular capillary hyperplasia, etc. But there's another study[16] shown that low-dose mifepristone only causes simple endometrial hyperplasia, without significant cellular atypia. Endometrial thickening can lead to breakthrough bleeding, sometimes so violent that hysterectomy is required. Long-term oral administration of mifepristone may also cause hypothyroidism and has been reported to cause severe liver damage[17].

The main pharmacokinetic characteristics of mifepristone are fast absorption, the peak dosage is only $0.81 \mathrm{~h}$, the utilization rate is up to $40 \%$, but the half-life is long. When mifepristone is used alone during an abortion, the elimination time of it from the body is generally 34 hours, which is relatively slow, and incomplete abortion may occur. In recent years, there have been many reports on the treatment of ectopic pregnancy with mifepristone. Compared with methotrexate, which has similar effects, mifepristone has no obvious adverse reaction, and the treatment success rate is higher, and it can also better reduce the pain of pregnant women. Studies have shown that the combined application of mifepristone and methotrexate can exert synergism on ectopic pregnancy, jointly promote mass absorption and reserve fertility of patients, and studies have also shown that this combination can improve the cure rate and security of ectopic pregnancy [18].

Methotrexate is an anti-tumor drug, mainly anti-folate. MTX binds effectively with folate reductase pharmacologically, and strongly inhibits dihydrofolate reductase in a competitive way, so that dihydrofolate cannot be transformed into tetrahydrofolate, which acts as a coenzyme in the synthesis of purine nucleotides and thymine nucleotides, thus destroying the synthesis of DNA, and competitively inhibiting the effective synthesis of DNA, RNA, and other proteins. So it is a commonly used clinical anti-tumor immunosuppressant.

MTX can also lead to embryonic cell necrosis by inhibiting the production of embryonic nourish cells, and it has a good curative effect in early treatment. Gestational trophoblastic cells have high sensitivity to methotrexate and they cannot continue to grow after EP patients take MTX, and the 
medRxiv preprint doi: https://doi.org/10.1101/2021.09.26.21264155; this version posted September 29, 2021. The copyright holder for this

preprint (which was not certified by peer review) is the author/funder, who has granted medRxiv a license to display the preprint in

All rights reserved. No reuse allowed without permission.

embryo will stop developing, eventually leads to necrosis, shedding of the embryo, which would gradually be absorbed [19][20].

In recent years, MTX has the best effect on conservative treatment of ectopic pregnancy. There are systemic administration and local administration of it. A study has shown that patients with low HCG levels can receive systemic administration of MTX instead of laparoscopic surgery. Systemic administration includes continuous intravenous administration and single intramuscular injection. It was shown that the clinical effective rates of continuous intravenous administration and single intramuscular injection were $94.9 \%$ and $96.2 \%$ respectively, and the incidence rate of blood cell count reduction were $16.7 \%$ and $3.9 \%$, which indicates that the difference between the curative effects of continuous intravenous administration and single intramuscular injection isn't significant. However, the incidence rate of blood cell count reduction in continuous intravenous dosing patients was significantly higher than that in those patients with single intramuscular injection. Thus, it is better to use single intramuscular injection treatments for patients with a low level of HCG, because of its better curative effect, simpler operation, and fewer adverse reactions, which brings higher clinical value [21].

The adverse reactions of methotrexate are related to many factors such as dosage, plasma concentration, and time of duration, which should be paid great attention to in clinical practice. Some studies have shown that[22], several minutes after taking MTX, folic acid in trophoblast cells accumulates constantly in the condition of being devitalized, leading to the inhibition of the synthesis of purine nucleotides and thymine nucleotides nourish cells and the death of trophoblast cells. Common adverse reactions of methotrexate in clinical application include myeloid suppression, nausea, vomiting, loss of appetite, abdominal pain and diarrhea and other gastrointestinal symptoms, oral ulcer and other skin mucosal symptoms, depression, anxiety, and other adverse emotions.

Mifepristone combined with methotrexate for ectopic pregnancy treatment was first reported by Perdu in 1998[23]. This pioneering study compared the curative effect of combination therapy with that of methotrexate therapy, reaching a result that the combination therapy can dissolve trophoblast cells more quickly than methotrexate therapy, so the combination therapy has a lower risk of rupture of the fallopian tube or peritoneal hemorrhage.

In recent years, combination therapy is more and more used in the treatment of ectopic pregnancy. Many studies [24] have shown that the curative effect of combination therapy is better than mifepristone therapy and methotrexate therapy, while the incidence rates of the three therapies aren't significantly different. Another research has shown that the cure rate of methotrexate therapy was $79.49 \%$, that of mifepristone therapy was $78.38 \%$ and that of mifepristone combined with methotrexate therapy was $90.91 \%$. What's more, a low dose of mifepristone combined with methotrexate showed high safety, significant curative effects, no obvious adverse reactions, and it's worthy of promotion clincally[25]. The mechanism of the combination therapy on EP is still unclear. It is speculated that the effect of methotrexate on the trophoblast may enhance the anti-decidual effect of mifepristone, leading to the destruction of the cervical trophoblast [26]. Some researchers believe that this is because the mechanisms and therapeutic targets of two drugs treating ectopic pregnancy are different, so their combination can play a synergism and enhance their curative effect. 
medRxiv preprint doi: https://doi.org/10.1101/2021.09.26.21264155; this version posted September 29, 2021. The copyright holder for this

preprint (which was not certified by peer review) is the author/funder, who has granted medRxiv a license to display the preprint in

All rights reserved. No reuse allowed without permission.

Although most researchers conclude that the curative effect of combination therapy is better than that of mifepristone therapy, however, some researchers still believe that the difference between their efficacy has no significance, saying that this is due to the poor quality of most trials, while combination therapy brings more adverse reactions. According to Rozenberg, P.'s article in 2003 [27], although many pieces of research have concluded that the efficacy of combination therapy was better than that of mifepristone therapy, they had the following defects limiting their interpretation of the research results: (1)their trials weren't double-blind trials; (2)the size of a small sample(25 per arm) was not based on the pre-specified calculation; (3)The random group method was not clearly stated. At present, there are few RCTs about the combination therapy on ectopic pregnancy, while there are lots of researches with uneven quality and different methods in China. Therefore, no accurate conclusion was drawn internationally. Besides, the practical application of combination therapy is less. There has been no meta-analysis of clinical trials in recent years at home and abroad. There was only one meta-analysis going back to 2011, but it was not registered and published on Prospero, and there was a lack of flow charts, basic information sheets, and a forest plot of outcome indicators.

To sum up, on the one hand, this study analyzes the efficacy and comes to a scientific conclusion, based on the epidemiological basis and pathogenesis of ectopic pregnancy, the pharmacological mechanism of combination between mifepristone and methotrexate, as well as existing researches. On the other hand, this study aims at filling the gap of relevant analysis in China and abroad, evaluating the advantages and disadvantages of inclusion trials, finding out the reasons why most of the research results are not reliable enough, and proposing measures for and scientific designing schemes.

\section{Methods}

\subsection{Protocol and Registration}

The protocol will be registered on the Prospero International Prospective Systems Evaluation Register. The system review will follow the preferred reporting items of the System Review and Meta-Analysis (PRISMA) statements and guidelines.

\subsection{Inclusion Criteria for Study Selection}

\subsubsection{Types of studies}

Clinical randomized controlled trials (RCTs) containing mifepristone combined with methotrexate therapy for ectopic pregnancy were included, with no limitation of language and publication status.

\subsubsection{Types of participants}

There are clear and recognized diagnostic criteria and efficacy criteria, and all patients are diagnosed as ectopic pregnancy, with stable vital signs, without broken mass or signs of active bleeding, without liver and kidney dysfunction or hematological system diseases,and their mass size in ultrasound examination as well as HCG level are match the condition of conservative treatment , regardless of age, marital status, gestational age and origin of the case. 
medRxiv preprint doi: https://doi.org/10.1101/2021.09.26.21264155; this version posted September 29, 2021. The copyright holder for this preprint (which was not certified by peer review) is the author/funder, who has granted medRxiv a license to display the preprint in

All rights reserved. No reuse allowed without permission.

\subsubsection{Types of interventions}

\subsubsection{Experimental interventions}

Including mifepristone therapy in combination with methotrexate therapy, without any other therapies.

\subsubsection{Control interventions}

The control group will receive only mifepristone therapy, without any other therapies.

\subsubsection{Types of outcome measures}

\subsubsection{Primary outcome}

The clinical recovery rate will be used as primary outcomes, with the criterion of recovery is clearly defined.

\subsubsection{Secondary outcomes}

After literature inclusion by primary outcome, all of the remaining outcome measures will be used as secondary outcomes, regardless of type.

\subsection{Exclusion criteria}

Non-randomized controlled trials include cross-over trial; Participants are scar pregnancy patients or cervical pregnancy patients; Chinese medicine therapy, operation therapy or other therapies as treatment in either group; Using different dosage or drug delivers between groups; More than one control group; Without recovery rate as outcome measure.

\subsection{Retrieval Strategy}

The literature of this study was retrieved from the three major English databases of Pubmed, Cochrane, and Embase, and the three major Chinese databases of CNKI, Wanfang, and Weipu. Randomized controlled trials published from October 2015 to October 2020 were selected. The retrieval strategy is shown in Table $\mathbf{1 .}$

The Chinese and English databases used different retrieval strategies to limit the literature published in the last five years, and the literature of non-RCT papers such as conference abstracts was manually searched and screened. In addition, there were no restrictions of language or publication.

\subsection{Data Extraction and Management}

\subsubsection{Literature Inclusion and Data Extraction.}

We will use Revmen5.4 to exclude the repetitive literature, and first exclude duplicate documents, and then by reading the title and abstract, filter the documents according to the inclusion and exclusion criteria. And we will read the full text of the remaining literature to obtain the final inclusion literature. 
medRxiv preprint doi: https://doi.org/10.1101/2021.09.26.21264155; this version posted September 29, 2021. The copyright holder for this preprint (which was not certified by peer review) is the author/funder, who has granted medRxiv a license to display the preprint in

All rights reserved. No reuse allowed without permission.

Data will be extracted according to the included literature, which contains general trial characteristics(authors and year), baseline patient and disease data(sample size, age, gender, and disease course), interventions(dosage and treatment course), details of the control interventions and outcomes (outcome measures, diagnostic criteria, adverse responses, and baseline) and other clinical data (basic therapy and common therapy). The inclusion process of this study will be carried out as shown in Figure 1.

\subsubsection{Methodological Quality Evaluation}

The risk of bias in trials will be assessed based on the following six items: random allocation, allocation concealment, blinding of participants, blinding of researchers, follow-up visit and complete cases, complete outcome measures. We categorized each item into one of these three levels-"high risk", "low risk" or"unknown risk". Those with low risk are scored 1 point, while those with high risk and unknown risk are not scored. The final bias score of each study is calculated to evaluate the overall risk: 0-2 is considered as overall high risk, 3-4 as unknown risk, and 5-6 as overall low risk.

\subsection{Statistical Analysis}

\subsubsection{Quantitative Data Synthesis}

Meta-analysis will be performed using Revman5.4 software(provided by Cochrane). In the results, the cure rate is dichotomous data, the other indicators are continuous variable data. Dichotomous data is expressed as the odds ratio (OR), and continuous data are expressed as mean difference(MD), both with a $95 \%$ confidence interval $(95 \% \mathrm{CI})$.

\subsubsection{Assessment of heterogeneity}

The heterogeneity test will be carried out first among all studies. Q test and $\mathrm{I}^{2}$ test will be used, and a specific analytic model will be chosen according to the test result. When $\mathrm{P}>0.1$ or $\mathrm{I}^{2}<50 \%$, which means there is obvious heterogeneity, the fixed-effect model will be used; When $\mathrm{P} \leq 0.1$ or $\mathrm{I}^{2} \geq 50 \%$, which means heterogeneity isn't obvious, the random-effect model will be used.

\subsubsection{Publication Bias}

When the number of literatures is $\geq 10$, the outcome indicators were analyzed by funnel plot of publication bias.

\subsubsection{Subgroup Analysis}

When there are different units in one outcome measure, data of different units will be classified into different subgroups, and then conduct subgroup analysis based on that.

\section{Discussion}

Patients with ectopic pregnancy who are young and childless should accept conservative treatment, for the reasons that the function of the oviduct can be protected from damage, and achieve an optimal treatment effect. Methotrexate is folic acid anti-metabolite, as well as a preferred medicine to treat 
medRxiv preprint doi: https://doi.org/10.1101/2021.09.26.21264155; this version posted September 29, 2021. The copyright holder for this preprint (which was not certified by peer review) is the author/funder, who has granted medRxiv a license to display the preprint in

All rights reserved. No reuse allowed without permission.

ectopic pregnancy admittedly. And mifepristone is a progestin antagonist, which also can destroy the embryo. However, there are limitations if only mifepristone is used. On the contrary, mifepristone combined with methotrexate to treat ectopic pregnancy can achieve mutual advantages and interaction, which brings advantages and potential in clinical application.

We will assess the efficacy of the combination of mifepristone and methotrexate to treat ectopic pregnancy comprehensively, by Meta-analysis based on the literature in recent years. Considering the quality of literature varies widely and international opinions to the efficacy are different, we expect that scientific conclusion about the efficacy can be shown through this analysis, and at the same time find out the primary cause to low quality of most trials and unreliable research results, to give some advice about how to improve the research and make scientific designing schemes, at the same time meeting the domestic and international research field's needs.

\section{Word Count}

\section{3,306 words}

\section{Documenting protocol amendments}

Protocol amendments and updates will be documented via PROSPERO online register. The description of the changes will be recorded, dated, and accessible along with the most up-to-date version within the record audit trail under the protocol registration.

Abbreviations: $\mathrm{CI}=$ confidence Interval, $\mathrm{OR}=$ odds ratio, $\mathrm{RCTs}=$ randomized controlled trials, $\mathrm{EP}=$ ectopic pregnancy.

\section{Author Contributions}

QS conceptualized the research idea, developed the research design, and drafted the manuscript. HF drafted and registered the protocol. TT, XL(Liao) and YL contributed to the study design. XL(Li) performed critical revision of this manuscript. All authors read and approved the final manuscript.

\section{Funding Statement}

This research received no specific grant from any funding agency in the public, commercial or not-for-profit sectors

\section{Competing Interests Statement}

The authors declare that the research was conducted in the absence of any commercial or financial relationships that could be construed as a potential conflict of interest.

\section{Ethics and Dissemination}

Not applicable

\section{Acknowledgements}


medRxiv preprint doi: https://doi.org/10.1101/2021.09.26.21264155; this version posted September 29, 2021. The copyright holder for this preprint (which was not certified by peer review) is the author/funder, who has granted medRxiv a license to display the preprint in All rights reserved. No reuse allowed without permission.

No acknowledgements

\section{References}

[1] Guan Guang. Analysis of misdiagnosis of 24 ectopic pregnancy cases[J]. Jilin Medical Journal, 2008(19): $1670-1671$.

[2] Le Jie. Obstetrics and gynecology [M]. 6th Ed. Beijing: People's Medical Publishing House, 2005:110.

[3] Liu Ying. Analysis on the incidence trend and clinical diagnosis and treatment of ectopic pregnancy [J]. China Min-Kang Medicine, 2014,26(09):64-65.

[4] Tang Lirong, Zheng Ping. Decadal changes of ectopic pregnancy risk factors [J]. Journal of Capital Medical University, 2010,31(06):817-820.

[5] Huang Yuzhu, Yang Youlian. Research trends and progress of diagnostic markers of ectopic pregnancy [J]. Inner Mongolia Medical Journal, 2016,48(02):178-180.

[6] Gao Cuiling. The value of quantitative detection of human chorionic gonadotropin in the early diagnosis of ectopic pregnancy [J].Journal of Shanxi Staff Medical College, 2018,28(06):21-23.

[7] Yang YuanYan. Observation and nursing care of 35 ectopic pregnancy cases used conservative treatment [J]. Qilu Nursing Journal, 2012,18(07):60-61.

[8] S. Wan, Y. Xiang, W. Fang, and D. Huang, "The effect of methotrexate in combination with mifepristone on ectopic pregnancy: a meta-analysis," International Journal of Clinical \&Experimental Medicine, vol. 9, no. 8, 2016.

[9] Spitz Irving M. Mifepristone: where do we come from and where are we going? Clinical development over a quarter of a century.. 2010, 82(5):442-52.

[10] Philippe Bouchard, Nathalie Chabbert-Buffet, Bart C.J.M. Fauser. Selective progesterone receptor modulators in reproductive medicine: pharmacology, clinical efficacy, and safety. 2011, 96(5):1175-1189.

[11] Carolyn L. Smith, Bert W. O’Malley. Coregulator Function: A Key to Understanding Tissue Specificity of Selective Receptor Modulators. 2004, 25(1):45-71.

[12] Feng Changyong, Meldrum Sean, Fiscella Kevin. Improved quality of life is partly explained by fewer symptoms after treatment of fibroids with mifepristone.. 2010, 109(2):121-4.

[13] Liu Mei-Ling, Shi Xin-Quan, Jia Meng-Chun. Differentially expressed genes in early gestational chorionic villi after administration of mifepristone. 2011, 27(6):371-378.

[14] Narvekar Nitish, Critchley Hilary O.D., Cheng Linan, et al. Mifepristone-induced amenorrhoea is associated with an increase in microvessel density and glucocorticoid receptor and a decrease in stromal vascular endothelial growth factor. 2006, 21(9):2312-2318. 
medRxiv preprint doi: https://doi.org/10.1101/2021.09.26.21264155; this version posted September 29, 2021. The copyright holder for this preprint (which was not certified by peer review) is the author/funder, who has granted medRxiv a license to display the preprint in

All rights reserved. No reuse allowed without permission.

[15] Fiscella Julietta, Bonfiglio Thomas, Winters Paul, et al. Distinguishing features of endometrial pathology after exposure to the progesterone receptor modulator mifepristone.. 2011, 42(7):947-53.

[16] Lakha F., Ho P.C., Van der Spuy Z.M., et al. A novel estrogen-free oral contraceptive pill for women: multicentre, double-blind, randomized controlled trial of mifepristone and progestogen-only pill (levonorgestrel). 2007, 22(9):2428-2436.

[17] Spitz IM, Grunberg SM, Chabbert-Buffet N, Lindenberg T, Gelber H, Sitruk-Ware R. Management of patients receiving long-term treatment with mifepristone. Fertil Steril. 2005 Dec;84(6):1719-26. doi: 10.1016/j.fertnstert.2005.05.056. PMID: 16359971.

[18] Chen Mingli. Clinical efficacy evaluation of mifepristone combined with methotrexate in the treatment of ectopic pregnancy [J]. Medical Frontier, 2017,7(2):86-87.

[19] Insogna Iris G, Farland Leslie V, Missmer Stacey A, et al. Outpatient endometrial aspiration: an alternative to methotrexate for pregnancy of unknown location.. 2017, 217(2):185.e1-185.e9.

[20] Tas Emre Erdem, Akcay Gulin Feykan Yegin, Avsar Ayse Filiz. Single-dose methotrexate for the treatment of ectopic pregnancy: Our experience from 2010 to 2015.. 2017, 33(1):13-17.

[21] Liu Qiqiu. Clinical treatment progress of ectopic pregnancy [J]. Journal of Applied Gynecology Endocrinology (Electronic Edition), 2016,3(06):136-137.

[22] Zhang Huanhuan, Fu Heng, Wang Hui.Clinical study on ectopic pregnancy treated by methotrexate combined with mifepristone with different administration method[J].Chinese Sexuality Journal, 2016,25(10):127-130.

[23] Marc Perdu, Erick Camus, Patrick Rozenberg, et al. Treating ectopic pregnancy with the combination of mifepristone and methotrexate: A phase II nonrandomized study. 1998, 179(3):640-643.

[24] Chen Xinlei, Zhang Junna.Clinical observation on the treatment of ectopic pregnancy with methotrexate, mifepristone, and their combination[J].China Maternal and Child Health Care, 2011,26(02):297-298.

[25] Lu Huiping. Comparison of the efficacy of two conservative treatment methods in 87 ectopic pregnancy cases [J]. China Maternal and Child Health Care, 2011,26(32):5101-5102.

[26] Heikinheimo O, Leminen A, Cacciatore B, Rutanen EM, Kajanoja P. Advanced cervical pregnancy: uterus-sparing therapy initiated with a combination of methotrexate and mifepristone followed by evacuation and local hemostatic measures. Acta Obstetricia et Gynecologica Scandinavica 2004;83:211-3.

[27] Rozenberg, P. (2003). Medical treatment of ectopic pregnancies: a randomized clinical trial comparing methotrexate-mifepristone and methotrexate-placebo. Human Reproduction, 18(9), 1802-1808. doi:10.1093/humrep/deg344 
medRxiv preprint doi: https://doi.org/10.1101/2021.09.26.21264155; this version posted September 29, 2021. The copyright holder for this preprint (which was not certified by peer review) is the author/funder, who has granted medRxiv a license to display the preprint in

All rights reserved. No reuse allowed without permission.

\section{Table 1}

PubMed retrieval strategies.

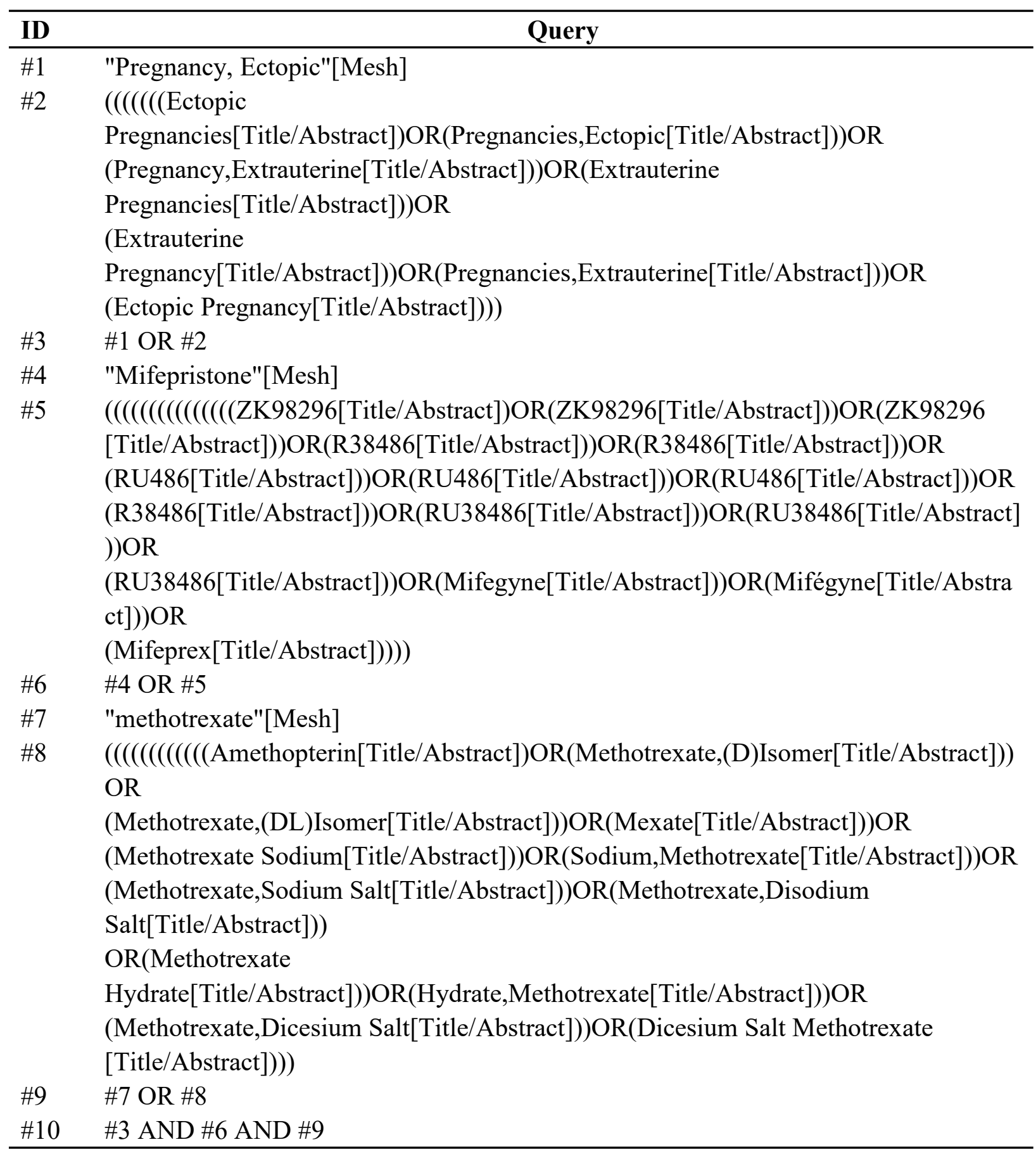

$\mathrm{Ab}=$ abstract, $\mathrm{Mesh}=$ medical subject headings, $\mathrm{Ti}=$ title. 


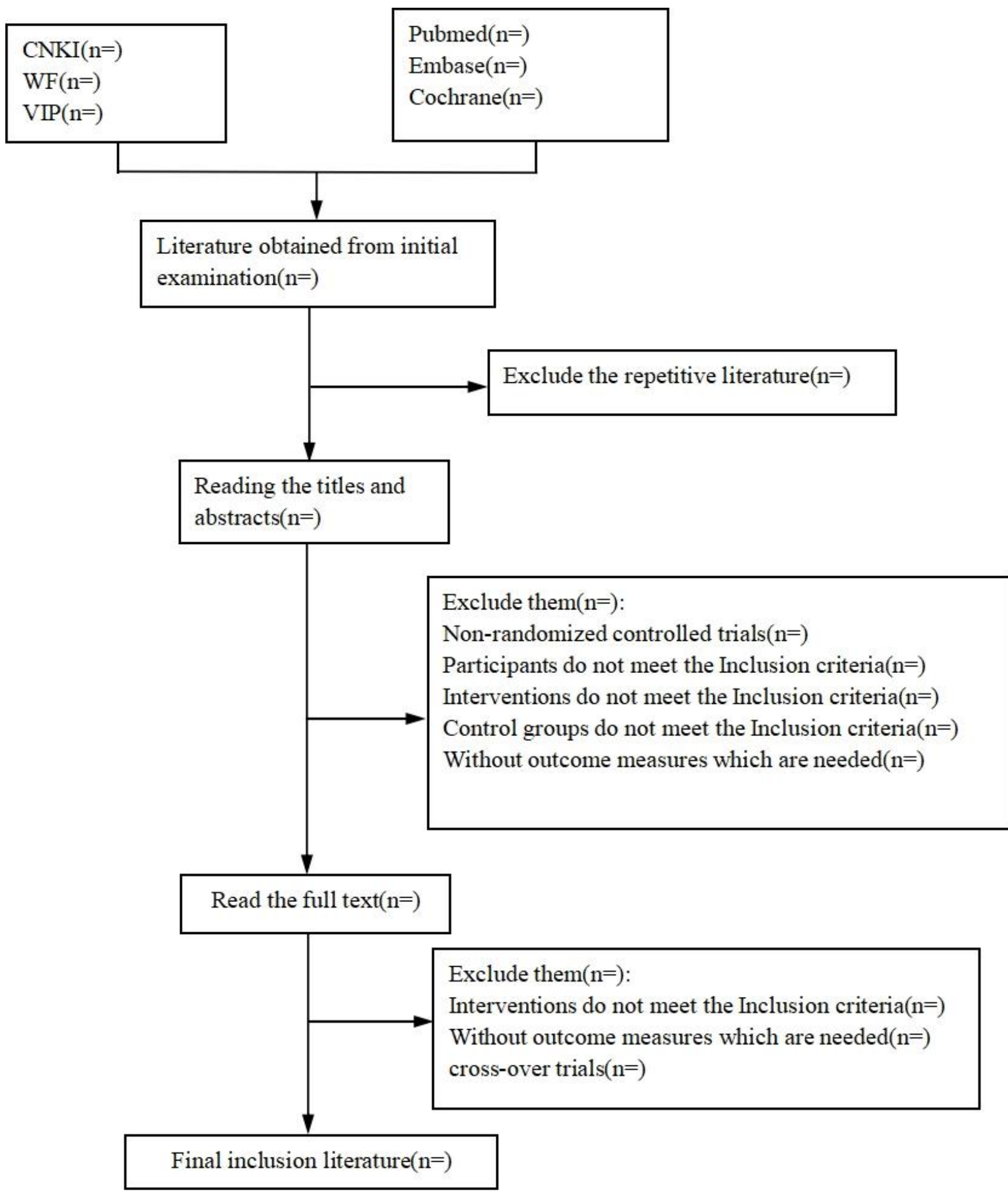

Figure 1. Literature selecting flow chart. 
$\mathrm{CNKI}(\mathrm{n}=)$

$\mathrm{WF}(\mathrm{n}=)$

$\operatorname{VIP}(\mathrm{n}=)$
Pubmed(n=)

Embase $(\mathrm{n}=)$

Cochrane $(\mathrm{n}=)$

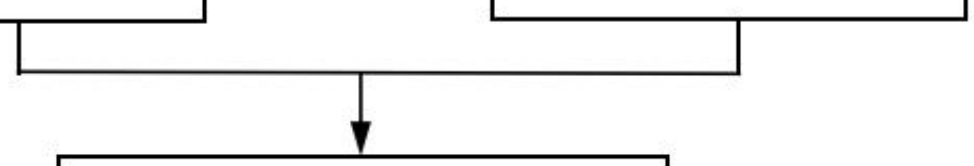

\section{Literature obtained from initial}

examination $(\mathrm{n}=)$

\section{Exclude the repetitive literature $(\mathrm{n}=)$}

Exclude them $(\mathrm{n}=)$ :

Non-randomized controlled trials $(\mathrm{n}=)$

Participants do not meet the Inclusion criteria( $\mathrm{n}=$ ) Interventions do not meet the Inclusion criteria $(\mathrm{n}=)$ Control groups do not meet the Inclusion criteria(n=) Without outcome measures which are needed(n=)

Reading the titles and $\operatorname{abstracts}(\mathrm{n}=)$
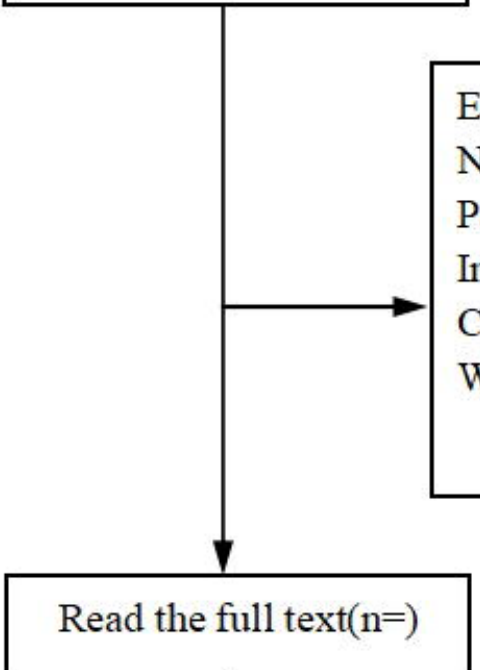

Exclude them $(\mathrm{n}=)$ :

Interventions do not meet the Inclusion criteria(n=) Without outcome measures which are needed $(n=)$ cross-over trials $(\mathrm{n}=)$

Final inclusion literature $(\mathrm{n}=)$

Figure 1. Literature selecting flow chart. 